\title{
Whitehead, CD Projekt RED e desenvolvimento de jogos: entrevista com Marcin Blacha
}

\section{Suely Fragoso}

Doutora; Universidade Federal do Rio Grande do Sul, Porto Alegre, RS, Brasil suelyfragoso@ufrgs.br

\section{Mariana Amaro}

Doutoranda; Universidade Federal do Rio Grande do Sul, Porto Alegre, RS, Brasil mari.amaroc@gmail.com

\section{Ian Wason Lane}

Graduando; Centro Universitário Ritter dos Reis, Porto Alegre, RS, Brasil irw.lane@gmail.com

Tradução:

Ian Wason Lane

Centro Universitário Ritter dos Reis, Porto Alegre, RS, Brasil

irw.lane@gmail.com

\section{Mariana Amaro}

Universidade Federal do Rio Grande do Sul, Porto Alegre, RS, Brasil

mari.amaroc@gmail.com

Revisão da Tradução:

Suely Fragoso

Doutora; Universidade Federal do Rio Grande do Sul, Porto Alegre, RS, Brasil suelyfragoso@ufrgs.br

\section{Resumo}

Entrevista com Marcin Blacha, designer de jogos e Diretor de Narrativa do estúdio CD Projekt RED sobre as conexões entre os estudos acadêmicos e o desenvolvimento de jogos. Blacha aborda a aproximação da Filosofia de Whitehead e o design de jogos, assim como temas referentes às singularidades dos jogos desenvolvidos fora do eixo anglófono.

\section{Palavras-chave}

Game Design. Filosofia do Organismo. Whitehead. CD Projekt RED. The Witcher. 
Designer de jogos e escritor, Marcin Blacha é o responsável pela adaptação da obra literária de Andrzej Sapkowski sobre o bruxo Geralt de Rivia ${ }^{1}$ para a série de games The Witcher (CD PROJEKT RED, 2007-2015). Mestre em Engenharia Eletroeletrônica pela Universidade de Ciência e de Tecnologia AGH (Akademia Górniczo-Hutnicza im. Stanisława Staszica), Blacha atua há 13 anos na equipe do estúdio polonês CD Projekt RED, onde ocupou os cargos de Designer Sênior e Escritor Principal (Lead Writer), trabalhando tanto na criação de roteiros e diálogos dos jogos e em questões ligadas ao design, como no planejamento dos elementos de gameplay e progressão do jogo. Em 2015, após o lançamento de The Witcher 3, foi promovido à função de Diretor de Narrativa (Story Director) e está atualmente trabalhando em Cyberpunk 2077, o próximo projeto da CD Projekt RED. Suas publicações acadêmicas incluem o artigo Processes and idleness in Europa Universalis 4 apresentado na Conferência Internacional da Philosophy of Computer Games (PoCG) de 2017, na Cracóvia (Polônia).

Nessa entrevista, realizada em inglês em julho de 2018 por e-mail, Blacha discorre sobre filosofia e games, focando principalmente na Filosofia do Organismo de Whitehad, sobre a relação entre a Academia e o desenvolvimento de jogos e sobre aspectos práticos do Game Design. Durante a entrevista também foram abordados a CD Projekt RED e seus projetos.

Entrevistas com você costumam concentrar-se na série The Witcher. Isso não surpreende, considerando o sucesso desses jogos e da centralidade de sua atuação na CD Projekt RED. Entretanto, nesta ocasião, tentaremos resistir à nossa curiosidade a respeito da série. Não será fácil, mas a nossa motivação principal é o trabalho que você apresentou na Conferência Philosophy of Computer Games (PoCG) em 2017. Naquele texto, você utilizou alguns conceitos de Whitehead para discutir características do gameplay de Europa Universalis 4. Foi uma combinação surpreendente

\footnotetext{
${ }^{1}$ No Brasil, a editora WMF Martin Fontes publicou uma coleção intitulada A saga do Bruxo Geralt de Rivia, com a tradução de sete obras de Andrzej Sapkowski (cinco romances e duas coletâneas de contos).
} 
que, na nossa opinião, você conduziu com grande êxito. No resumo de seu texto para a PoCG 2017 você afirmou que considera a filosofia de Whitehead particularmente adequada para descrever gameplay, assim como games em geral. Gostaríamos de saber mais sobre os fundamentos dessa sua opinião, considerando que 0 público da Intexto é predominantemente acadêmico, porém não da área da Filosofia.

A Filosofia do Organismo de Whitehead (1978) descreve a realidade como um processo, um cosmo de eventos inter-relacionados, em constante mutação. Ocasiões verdadeiras, gotas de experiência que constituem a realidade, existem apenas no ato de transformação e eventualmente desaparecem quando atingem sua intenção subjetiva. Criamos videogames para imitar o nosso mundo, então podemos olhar para eles como modelos simplificados desse mundo - microcosmos governados pelas regras implementadas. Ocasiões verdadeiras encontram sua satisfação na beleza e, se concordarmos que queremos falar de videogames em termos da Filosofia de Whitehead (1927, 1978), nós encontramos um framework útil que vincula ontologia e estética em um território mútuo, o da experiência. Nesse framework, videogames são desenvolvidos para entreter os jogadores, mas eles também são parte da natureza, como o pôr-do-sol e o ecossistema tropical, e o jogador está incluído apenas como mais um elemento entre outros. São processos inter-relacionados, projetados por humanos, mas quando são jogados não estão mais inteiramente sob controle humano. Criatividade é a categoria derradeira para a atividade de jogar, assim como para a realidade em geral. Além disso, quando pensamos sobre um jogo em termos da filosofia Whiteheadiana, podemos definir um jogo como uma proposição que é recriada por um jogador no processo de jogá-lo. Essa abordagem nos ajuda a perceber, de maneira mais ampla, os complicados sistemas de relações entre os elementos do jogo, em que o jogo, o jogador e o ambiente do jogador são igualmente importantes.

Também estamos interessados em conhecer sua visão sobre a relação entre os estudos acadêmicos e os produtores de jogos. Quais são os 


\section{benefícios (e as potenciais desvantagens) que você identifica ao unir essas duas pontas?}

O desenvolvimento de jogos se foca nos aspectos práticos. Jogos são criados com a intenção de entreter os jogadores. Os desenvolvedores são cautelosos ao aplicar novidades em termos de design. Mesmo os produtores indies, em alguma medida, seguem as regras quando tentam inovar. Existem jogos de vanguarda, mas muito poucos são notados, o resto acaba sendo taxado como "estranho". A indústria dos games é conservadora porque é um negócio. Funciona como os artesãos medievais fazendo vitrais - cada geração segue os padrões deixados por seus antecessores. Estudos acadêmicos, por outro lado, descrevem os videogames como fenômenos e se interessam por aspectos que os desenvolvedores acham pouco prático. Na intersecção entre esses dois mundos, a abordagem prática se encontra com o pensamento abstrato. Dois mundos colidem e daí nasce a inovação. Como começamos com Whitehead, vou lembrar que a criatividade é a categoria derradeira da existência e, no cosmo orgânico, a inovação nasce da criatividade. Isso significa que em toda direção há um fluxo de informação e ideias para se tomar uma decisão e alcançar a satisfação. Em minha opinião, é assim que a cooperação entre a academia e os desenvolvedores de jogos deveria ser. Eu tenho meu próprio exemplo pessoal - minha missão de vida é criar um videogame sobre Safo. Esse projeto nasceu da paixão pelos versos dela e terminou comigo lendo artigos sobre grego Eólico, cultura Jônica e poesia lírica antiga. Eu aprendi não apenas sobre o que seria o meu jogo, mas também como projetar o gameplay. 0 conhecimento acadêmico me obrigou a descartar minhas ideias e começar do zero. Agradeço ao mundo acadêmico por isso!

\section{Os conceitos e trabalhos de Whitehead deram apoio ou serviram de inspiração para seus trabalhos na CD Projekt RED? E quanto a outros filósofos?}

Há algum tempo eu descobri que nosso método de design narrativo é a implementação de uma abordagem Whiteheadiana à educação e ao pensamento especulativo. Isso quer dizer que Whitehead talvez seja o mais bem-sucedido teórico de 
design de narrativas para videogames, entre os metafísicos. Ao invés de descrever a metodologia da nossa linha de produção e de desenvolvimento vou recomendar a leitura de Os Fins da Educação (1969) e do início de Processo e Realidade (2010). Alguém pode perguntar: Por que educação? Por que ler? A resposta é que se você trabalha com histórias para videogames por 13 anos e você não pensa nesse processo em termos de aprendizado, uma hora você vai falhar. Outros filósofos não têm tanta sorte [quanto Whitehead] - nós geralmente fazemos referência a eles em Easter eggs ${ }^{2}$ no jogo. Talvez Platão, minha outra paixão, seja uma exceção, porque ele inspirou a discussão sobre o que é justiça na expansão Blood \& Wine [de The Witcher 3]. Nos jardins da duquesa Anna Henrietta [personagem do jogo] existe um filósofo que cita $A$ República de Platão. Com ele, você pode aprender sobre os deveres dos guardiões (cavaleiros).

Já que direcionamos as questões à CD Projekt RED, vamos perguntar sobre certas peculiaridades que nos intrigam, especialmente em função de várias similaridades que vemos entre o Brasil e a Polônia. Como foi desenvolver um jogo AAA com um time considerado de primeira qualidade (cujos produtos são ansiosamente esperados ao redor do mundo) estando fora do eixo anglófono? Mais especificamente, que aspectos você vê no seu estúdio de games que não são normalmente encontrados em estúdios de países mais predominantes?

Em poucas palavras, sermos Eslavos e Europeus-orientais nos dá singularidade e nós fomos espertos o suficiente para aplicarmos isso como parte de nossa cultura de trabalho e à alma de nossos jogos. Não tenho experiência suficiente para comparar a CD Projekt RED com outros estúdios, mas tenho certeza que nosso amor pela liberdade e pela independência ajudou muito. Nós temos a cabeça aberta e não temos medo de arriscar. Acima de tudo, nós acreditamos que games melhores são produzidos quando temos conhecimento de nossa história, cultura e amor pelas coisas que nos moldam mesmo quando estas são memórias

\footnotetext{
2 "Easter eggs" são segredos ou conteúdos escondidos dentro de programas, sites, jogos ou outros produtos audiovisuais que fazem referência a elementos externos ao mundo ficcional ao qual está inserido.
} 
fugidias da infância ou impressões que são difíceis de expressar no processo criativo de fazer um jogo.

O que poderia distinguir uma Escola Eslava de desenvolvimento e design de jogos de outros estilos? Mais claramente, quais características você acredita que diferenciam essa Escola da Japonesa e dos países de língua inglesa?

Os poloneses, e eu penso que isso se aplica a todos os eslavos, têm muito interesse em história. Quando você escuta os discursos públicos, os políticos ou os programas de TV, todos são ancorados no passado. Somos influenciados pela história recente e temos conhecimento de que tudo tem raízes em eventos distantes. Nada é simples, tudo é um legado de eventos prévios, e para contar uma história é preciso lembrar-se das próprias origens e manter a complexidade dos significados, mesmo que a história em si seja simples. Então, quando se trata de criar videogames, aceitamos os padrões anglófonos, mas temos um ímpeto de complicá-los com adaptações locais. Somos realistas e pessimistas e isso também influencia os jogos que fazemos.

Seu novo projeto, Cyberpunk 2077, é muito diferente do mundo ficcional de The Witcher. Ainda assim, parece que há uma resistência à cultura colonialista anglófona nele, uma vez que os personagens não falarão inglês. A CD Projekt RED pretende enfrentar o desafio de transportar um gênero, o ciberpunk, para outro contexto que não lhe é usual? Por quê?

Os personagens vão falar inglês, assim como outras línguas. Não posso falar muito sobre Cyberpunk 2077, mas nós certamente vamos tentar ressuscitar o gênero. 
O ciberpunk, enquanto gênero, inspirou muitos conceitos, teorias e até modelos na chamada "cibercultura" Podemos esperar sinais de trabalhos acadêmicos relacionados a essa escola de pensamento ou outras no novo jogo?

Estamos usando muitas fontes de inspiração para criar o jogo, e isso inclui trabalhos acadêmicos. No momento eu não posso dizer quais trabalhos especificamente, pois não quero dar pistas sobre o enredo.

Apesar de tentarmos evitar falar em The Witcher, há uma questão à qual não vamos conseguir resistir. Algumas teorias acadêmicas podem ser relacionadas à história original, mas existiram trabalhos acadêmicos específicos que inspiraram a CD Projekt RED no processo de "tradução" da literatura para o jogo?

Nós não seguimos nenhuma orientação acadêmica específica. Estávamos apenas tentando fazer o melhor jogo possível, usando nosso conhecimento e nossa paixão pelo mundo de The Witcher. 0 que nós aprendemos dos livros de Sapkowski que o enredo e os personagens são os elementos mais importantes e o resto é apenas secundário. Estávamos sempre tentando aplicar essa abordagem, especialmente no The Witcher 3, em que o design de cada missão do jogo iniciou com o estabelecimento de relações entre os personagens. Eventualmente nós acabamos com um mundo estimulante, que se tornou mais memorável que alguns personagens. Acho que o meio (videogame) requer um mundo desse tipo. Ou talvez nós começamos a pensar sobre o mundo como se ele fosse um personagem, sendo ele (o mundo) o principal antagonista do Geralt?

No Brasil, e especificamente na área metropolitana de Porto Alegre, onde a universidade responsável pela revista Intexto está localizada, existem 
diversos cursos voltados à formação e à produção de jogos. Entre eles estão cursos de duração mais curta, com abordagens mais técnicas, por exemplo, voltados para a programação ou modelagem 3D. Outros cursos são graduações, com três ou quatro anos de duração, que abrangem cultura dos games, game design e implementação. Existe algum conteúdo específico que você recomendaria às instituições responsáveis por esses cursos, que incluam (ou evitem), para fortalecer os profissionais que eles estão preparando?

Quanto mais oficinas e trabalho em jogos reais, melhor. Os cursos mais bem-sucedidos que eu conheço focam na criação de pequenos jogos usando Unity ou Unreal ou outro software comercial. Além dos talentos práticos, essa abordagem ensina como cooperar em times e que finalizar os últimos $10 \%$ do jogo leva dez vezes mais tempo que os outros $90 \%$.

\section{Referências}

BLACHA, Marcin. Processes and idleness in Europa Universalis 4. In: THE PHILOSOPHY OF COMPUTER GAMES CONFERENCE, 11., 2017, Kraków. Proceedings [...]. Kraków: Jagiellonian University in Krakow, 2017. p. 1-5.

WHITEHEAD, Alfred North. Os fins da educação: e outros ensaios. Traduzido por Leônidas Gontijo de Carvalho. São Paulo: Companhia Editora Nacional, 1969.

WHITEHEAD, Alfred North. Process and reality: an essay in cosmology. New York: The Free Press, 1978.

WHITEHEAD, Alfred North. Processo e realidade: ensaio de cosmologia. Lisboa: Centro de Filosofia da Universidade de Lisboa, 2010.

WHITEHEAD, Alfred North. Symbolism: it's meaning and effect. New York: Macmillan, 1927.

PARADOX INTERACTIVE. Europa universalis IV. Jogo Digital. PC, 2013

CD PROJEKT RED. The witcher 3: wild hunt. Jogo Digital. PC, XBOX ONE, Playstation 4, 2015.

CD PROJEKT RED. The witcher 3: blood \& wine. Expansão de Jogo Digital. PC, XBOX ONE, Playstation $4,2016$. 
CD PROJEKT RED. Jogo Digital. Cyberpunk 2077. [s.d].

\title{
Whitehead, CD Projekt RED and games development: interview with Marcin Blacha
}

\begin{abstract}
Interview with Marcin Blacha, game designer and Narrative Director of CD Projekt RED game studio about the relationship between academic studies and game development. Blacha addresses the approach of Whitehead's Philosophy and game design, issues concerning the singularities of games developed outside the anglophone world.
\end{abstract}

\section{Keywords}

Game Design. Philosophy of Organism. Whitehead. CD Projekt RED. The Witcher. 